\title{
Unexpected uterine sarcomas after hysterectomy and myomectomy for presumed leiomyoma: a retrospective study of 26,643 patients
}

This article was published in the following Dove Press journal: Cancer Management and Research

\author{
Hanyu Cao',* \\ Lin $\mathrm{Li}^{1, *}$ \\ Bowen Yang ${ }^{2}$ \\ Gupo Luo² \\ Jiangyan Lou' \\ Mingrong $\mathrm{Xi}^{1, *}$ \\ 'Department of Gynecology and \\ Obstetrics, West China Second University \\ Hospital, Sichuan University, Chengdu City, \\ Sichuan Province, People's Republic of \\ China; ${ }^{2}$ Key Laboratory of Birth Defects \\ and Related Diseases of Women and \\ Children, West China Second Hospital, \\ Sichuan University, Chengdu City, Sichuan \\ Province, People's Republic of China \\ *These authors contributed equally to this \\ work
}

\begin{abstract}
Objectives: We conducted this study to explore the clinical characteristics, prognosis, and prevalence of unexpected uterine sarcoma (UUS) after hysterectomy and myomectomy for presumed leiomyoma.

Study design: The records of women who underwent hysterectomy or myomectomy through laparoscopy or laparotomy for preoperatively presumed uterine leiomyomas from January 2009 to December 2016 were reviewed and data were retrospectively analyzed.

Results: Eleven patients had morcellation of uterine sarcoma. Eighty-eight patients were diagnosed with uterine sarcomas (total prevalence: $0.33 \%$ ) including 29 leiomyosarcomas (LMS), 48 endometrial stromal sarcomas (ESS), and 11 adenosarcomas. ESS patients with advanced stage were significantly associated with worse overall survival $(p<0.01)$.

Conclusion: Only $0.33 \%$ of patients who underwent surgery for presumed leiomyoma experienced UUS, and advanced stage seemed to be the single prognostic factor for sarcoma. However, the time interval between initial treatment and secondary definitive surgery was not shown to impact prognosis. In addition, the small number of UUS patients having morcellation (4 LMS and 7 ESS) may be underpowered to detect differences in survival.
\end{abstract}

Keywords: adenosarcomas, endometrial stromal sarcomas, leiomyosarcomas, morcellation, prognosis

\section{Introduction}

Uterine leiomyomas or fibroids are benign neoplasms that arise from smooth muscles of the uterus, with an incidence of nearly $70 \%$ in white women by age 50 and $>80 \%$ for black women. ${ }^{1}$ As the most common indication for hysterectomy in the United States, leiomyomas impose a heavy burden on health care costs annually. ${ }^{2}$ The majority of patients are asymptomatic, while up to $40 \%$ report symptoms such as prolonged menstruation or menorrhagia, abdominal pain, urinary complaints, and even infertility. ${ }^{3}$ Transvaginal ultrasound serves as the most cost-effective adjuvant method to diagnose a pelvic mass, providing both high sensitivity and specificity. Nevertheless, it may still be difficult to distinguish between myomas and malignant sarcomas preoperatively as they resemble each other in appearance. Uterine sarcomas are a rare heterogeneous group, originating from the smooth muscle or mesenchyme of the uterus comprising leiomyosarcoma (LMS), endometrial stromal sarcoma (ESS), adenosarcoma, undifferentiated sarcoma, and other rare subtypes. Surgical resection remains the gold standard for uterine sarcomas, including total abdominal hysterectomy with or without bilateral salpingo-oophorectomy, while the role of
Correspondence: Mingrong Xi

Department of Gynecology and

Obstetrics, West China Second

University Hospital, Sichuan University, 17

Renmin South Road, Chengdu City,

Sichuan Province, People's Republic of

China

Tel +86 I 8180609008

E-mail xmrjzz@I26.com 
lymphadenectomy remains controversial. ${ }^{4}$ The prevalence of uterine sarcomas found incidentally during or after surgery for presumed myomas varies from $0 \%$ to $0.6 \% .^{5-8}$ Overall survival (OS) rates are reported to be $<50 \%$ even in early stages. ${ }^{9}$ Prognosis is especially poor in LMS, in which the tumor size has been reported as a major prognostic indicator. ${ }^{10-12}$ Owing to the nonspecific symptoms and histologic variety, there is no evidence-based consensus regarding prognostic factors and optimal management. ${ }^{13}$

The present study was conducted to provide a retrospective analysis of unexpected uterine sarcoma (UUS) during an 8-year period while analyzing clinicopathologic features and identifying the prognostic value of previously proposed indicators. In addition, we explore whether the timing of reoperation plays an important role in the prognosis of uterine sarcomas.

\section{Materials and methods}

This study was approved by the Ethics Committee of West China Second University Hospital, a tertiary hospital in Southwest China, and was carried out following the principles of the Helsinki Declaration. Informed consent was waived due to the retrospective of the study which involves only data analysis of existing medical records, patients' privacy was not breached and the patient's informed consent is not required. The records of uterine sarcoma patients who underwent surgical treatment for presumed leiomyoma from March 2009 to December 2016 were retrospectively reviewed. All cases of incidentally discovered LMS, ESS, and adenosarcomas were included. The diagnosis of uterine sarcoma was confirmed by gynecologic pathologists in West China Second University Hospital at the time of surgery. A tumor is diagnosed as LMS rather than smooth muscle tumor of uncertain malignant potential STUMP if it had either: 1) geographic necrosis; 2i) $\geq 10$ mitoses per 10 high-power fields plus diffuse or multifocal atypia (moderate-severe). Relevant information was extracted including age at diagnosis, gravidity, parity, menopausal state, body mass index (BMI), chief complaint, tumor size, stage, type of initial surgery (hysterectomy or myomectomy), method of initial surgery (laparoscopy or laparotomy), morcellation, secondary surgery, lymphadenectomy, lymph node metastasis, lymphovascular invasion, and adjuvant treatment (chemotherapy and radiotherapy). Staging was based on the International Federation of Gynecology and Obstetrics 2009 classification system. For patients who had undergone secondary surgery, the time interval between first and second surgery was included in the analysis and separated into two groups ( $\leq 30$ days, $>30$ days).

OS was defined as the period from diagnosis to either the day of death or last visit. All statistical tests were performed using SPSS software version 18.0 (SPSS, Inc, Chicago, IL, USA). Survival analyses were performed with Kaplan-Meier survival curves, and a Cox proportional hazards model was used to assess the prognostic variables of interest. A two-tailed probability value of $<0.05$ on univariate analysis was considered statistically significant and was used for inclusion in the multivariate analyses. Proportional hazards assumption test has been done by using time-dependent covariates.

\section{Results}

\section{Incidence of UUS and LMS}

During the 8-year period, 26,643 patients underwent hysterectomy or myomectomy by laparoscopy or laparotomy for preoperatively presumed uterine leiomyomas in our hospital. A total of 88 patients were diagnosed with UUS, pathologically confirmed during or after surgery, with the total prevalence of UUS being $0.33 \%$ and the prevalence of LMS being $0.11 \%$. Among these, 4183 patients underwent laparoscopic hysterectomy, 7133 underwent total abdominal hysterectomy, 6902 had laparoscopic myomectomy, and 8425 had abdominal myomectomy. The incidence of these four groups is presented in Table 1.

Table I Incidence of unexpected uterine sarcoma found at hysterectomy or myomectomy

\begin{tabular}{|l|l|l|l|l|l|}
\hline & \multicolumn{2}{l|}{ Hysterectomy } & \multicolumn{2}{l|}{ Myomectomy } & Total number \\
\cline { 2 - 6 } & Laparoscopy & Laparotomy & Laparoscopy & Laparotomy \\
\hline UUS, n & 11 & 47 & 13 & 17 & 88 \\
LMS, n & 4 & 16 & 4 & 5 & 29 \\
Total, $\mathrm{n}$ & 4183 & 7133 & 6902 & 8425 & 26,643 \\
Rate of UUS (\%) & 0.26 & 0.66 & 0.19 & 0.20 & 0.33 \\
Rate of LMS (\%) & 0.10 & 0.22 & 0.60 & 0.60 & 0.11 \\
\hline
\end{tabular}

Abbreviations: LMS, leiomyosarcomas; UUS, unexpected uterine sarcomas. 


\section{Clinicopathologic features}

Patient characteristics are shown in Table 2. Forty-eight (54.6\%) patients were diagnosed with ESS, including 45 low-grade and 3 high-grade ESS. Twenty-nine (33\%) patients had LMS, and the remaining 11 (12.5\%) patients had adenosarcomas. The median age of all included patients at diagnosis was 45 (range 17-78) years. Patients with adenosarcomas were older than patients in the other groups. Gravidity and parity ranged from 0 to 8 and 0 to 6 in LMS and ESS, respectively. Forty-eight percent of patients were premenopausal and 52\% were perimenopausal/postmenopausal. Patients with LMS had the highest median BMI of $24.56(16.19-31.18) \mathrm{kg} / \mathrm{m}^{2}$. Prolonged menstruation or menorrhagia was the most common primary complaint for all three groups, followed by palpable mass. The largest tumor size $>5 \mathrm{~cm}$ was found in $18(81.81 \%)$ LMS, 22 (51.16\%) ESS, and $4(50 \%)$ adenosarcoma patients, respectively. Most LMS patients (96.6\%) were diagnosed at stage I compared with ESS $(83.3 \%)$ and adenosarcoma (90.9\%). For their first surgery, $69 \%$ of LMS, $58.3 \%$ of ESS, and $90.9 \%$ of adenosarcoma patients underwent hysterectomy rather than myomectomy while $72.4 \%$ of LMS, $75 \%$ of ESS, and $63.6 \%$ of adenosarcoma underwent laparotomy instead of laparoscopy. A total of $11(12.5 \%)$ patients had morcellation during surgery including 4 LMS and 7 ESS patients. In 66 (75\%) patients who underwent reoperation, 39 (59.1\%) had their secondary surgery within 30 days. Among 62 $(70.5 \%)$ patients who underwent lymphadenectomy including removal of pelvic and/or para-aortic lymph nodes, only 4 patients with ESS were found to have lymph node metastasis. Moreover, the rate of lymphovascular space invasion was $17.2 \%$ in LMS, $27.1 \%$ in ESS, and $9.1 \%$ in adenosarcoma patients. A total of $37(42.1 \%)$ patients did not receive any additional treatment, while 41 (46.6\%) had chemotherapy, and 10 (11.4\%) received both chemotherapy and radiotherapy.

\section{Prognostic factors and outcomes}

Median follow-up for all 88 UUS patients was 60 (range: 13-102) months. For each specific subtype, median follow-up was 48 (range: 13-100) months for LMS, 61 (range: 15-102) months for ESS, and 68 (range: 15-102) months for adenosarcomas, respectively. Relapses occurred in 21 patients, including 10 LMS, 6 ESS, and 5 adenosarcomas. Twenty patients died of their diseases including 9 LMS, 6 ESS, and 5 adenosarcomas. The unadjusted 5-year cumulative OS rates for the three histologic subtypes were compared separately using logrank test, and the corresponding Kaplan-Meier curves are shown in Figure 1. ESS patients had a favorable OS rate of $87.2 \%$ (95\% CI: 77.6-96.8\%) compared with patients with LMS (OS: 65.3\%, 95\% CI: 45.1-85.5\%) and adenosarcoma (OS: 59.7\%, 95\% CI: 28.5-90.9\%). Log-rank test showed that there were no significant differences among the three groups only for OS $(p=0.06)$. For the univariate analysis, stage II-IV ESS patients showed a significantly poorer OS rate compared with stage I patients (95\% vs $50 \%, p<0.01$; Figure 2). The results of multivariate analysis also revealed stage to be the unique prognostic factor for ESS patients. However, other indicators, including age, gravidity, parity, menopausal status, BMI, chief complaints, surgical procedure, lymphovascular space invasion, lymph node metastasis, or adjuvant treatment did not show a significant impact on survival.

\section{Discussion}

Uterine sarcomas are rare and aggressive tumors accounting for $<5 \%$ of all uterine malignancies. ${ }^{13}$ Previously, they were classified as carcinosarcomas (40\%), LMS (40\%), ESS (15\%), undifferentiated sarcoma (5-10\%), and adenosarcomas $(5 \%){ }^{14,15}$ The International Federation of Gynecology and Obstetrics reclassified carcinosarcoma as an undifferentiated carcinoma of the endometrium in 2009 because of recent evidence regarding molecular and genetic origins, though others claimed that it displayed a higher rate of extrauterine spreading and recurrence than endometrial carcinoma. ${ }^{16,17}$ As a result, carcinosarcoma was excluded from the present study.

In the current study, ESS was the main subtype, similar to the results of Zhang et al and Gao et al in a Chinese population. ${ }^{18,19}$ In the current study, 66 UUS patients underwent hysterectomy or myomectomy initially and then a second surgery, 17 of them were upstaged, Cusido et al and Lee et al demonstrated no difference in survival of patients undergoing hysterectomy or myomectomy as their initial surgery. ${ }^{20,21}$ Morcellation was demonstrated to be an independent prognostic indicator in previous studies by increasing intraperitoneal spreading. ${ }^{22,23}$ However, in the current study, the small number of UUS patients having morcellation (4 LMS and 7 ESS) may be underpowered to detect differences in survival. Lymphadenectomy was performed in $68.9 \%$ of UUS patients in the current study, whereas revealing no survival benefit in UUS. In addition, according to a study 
Table 2 Characteristics of patients diagnosed with unexpected uterine sarcoma

\begin{tabular}{|c|c|c|c|c|}
\hline Characteristic & Total $(n=88)$ & LMS (n=29) & ESS $(n=48)$ & Adenosarcoma $(n=I I)$ \\
\hline Median age, years (range) & $45(17-78)$ & $44(31-68)$ & $43(17-66)$ & $48(30-78)$ \\
\hline Median gravidity (range) & $3(0-8)$ & $3(0-8)$ & $3(0-6)$ & $2(0-5)$ \\
\hline Median parity (range) & I (0-6) & I (0-6) & I (0-6) & I (0-2) \\
\hline \multicolumn{5}{|l|}{ Menopausal status, $\mathrm{n}$} \\
\hline Premenopause, $\mathrm{n}$ & 42 & 15 & 22 & 5 \\
\hline Perimenopause/postmenopause, $n$ & 46 & 14 & 26 & 6 \\
\hline Body mass index, $\mathrm{kg} / \mathrm{m}^{2}$ & $23.18(16.02-31.18)$ & $24.56(16.19-31.18)$ & $22.83(16.02-29.38)$ & $21.01(16.23-30.43)$ \\
\hline$\leq 23$ & 41 & 13 & 22 & 6 \\
\hline$>23$ & 44 & 15 & 24 & 5 \\
\hline
\end{tabular}

Primary complaints

\begin{tabular}{|c|c|c|c|c|}
\hline $\begin{array}{l}\text { Asymptomatic, } n \\
\text { Pelvic pain, } n \\
\text { Prolonged menstruation or menorrhagia, } n \\
\text { Palpable mass, } n \\
\text { Other complaints, } n\end{array}$ & $\begin{array}{l}12 \\
13 \\
31 \\
21 \\
11\end{array}$ & $\begin{array}{l}6 \\
5 \\
9 \\
7 \\
2\end{array}$ & $\begin{array}{l}4 \\
7 \\
18 \\
12 \\
7\end{array}$ & $\begin{array}{l}2 \\
1 \\
4 \\
2 \\
2\end{array}$ \\
\hline \multicolumn{5}{|l|}{ Stage } \\
\hline $\begin{array}{l}\mathrm{I}, \mathrm{n} \\
\mathrm{II}-\mathrm{IV}, \mathrm{n}\end{array}$ & $\begin{array}{l}78 \\
10\end{array}$ & $\begin{array}{l}28 \\
1\end{array}$ & $\begin{array}{l}40 \\
8\end{array}$ & $\begin{array}{l}10 \\
1\end{array}$ \\
\hline \multicolumn{5}{|l|}{ First surgery } \\
\hline $\begin{array}{l}\text { Hysterectomy, n } \\
\text { Myomectomy, n } \\
\text { Laparoscopy, n } \\
\text { Laparotomy, n }\end{array}$ & $\begin{array}{l}58 \\
30 \\
24 \\
64\end{array}$ & $\begin{array}{l}20 \\
9 \\
8 \\
21\end{array}$ & $\begin{array}{l}28 \\
20 \\
12 \\
36\end{array}$ & $\begin{array}{l}10 \\
1 \\
4 \\
7\end{array}$ \\
\hline \multicolumn{5}{|l|}{ Morcellation } \\
\hline $\begin{array}{l}\text { Yes, } n \\
\text { No, } n\end{array}$ & $\begin{array}{l}11 \\
77\end{array}$ & $\begin{array}{l}4 \\
25\end{array}$ & $\begin{array}{l}7 \\
41\end{array}$ & $\begin{array}{l}0 \\
11\end{array}$ \\
\hline \multicolumn{5}{|l|}{ Second surgery } \\
\hline $\begin{array}{l}\text { Yes, } \mathrm{n} \\
\text { Time interval } \leq 30, \mathrm{n} \\
\text { Time interval }>30, \mathrm{n} \\
\text { No, } \mathrm{n}\end{array}$ & $\begin{array}{l}66 \\
39 \\
27 \\
22\end{array}$ & $\begin{array}{l}24 \\
15 \\
9 \\
5\end{array}$ & $\begin{array}{l}37 \\
22 \\
15 \\
11\end{array}$ & $\begin{array}{l}5 \\
2 \\
3 \\
6\end{array}$ \\
\hline \multicolumn{5}{|l|}{ Lymphadenectomy } \\
\hline $\begin{array}{l}\text { Yes, } n \\
\text { No, } n\end{array}$ & $\begin{array}{l}61 \\
27\end{array}$ & $\begin{array}{l}25 \\
4\end{array}$ & $\begin{array}{l}30 \\
18\end{array}$ & $\begin{array}{l}6 \\
5\end{array}$ \\
\hline \multicolumn{5}{|l|}{ Lymph node metastasis } \\
\hline $\begin{array}{l}\text { Positive, n } \\
\text { Negative, n }\end{array}$ & $\begin{array}{l}4 \\
57\end{array}$ & $\begin{array}{l}0 \\
25\end{array}$ & $\begin{array}{l}4 \\
26\end{array}$ & $\begin{array}{l}0 \\
6\end{array}$ \\
\hline \multicolumn{5}{|l|}{ Lymphovascular space invasion } \\
\hline $\begin{array}{l}\text { Yes, n } \\
\text { No, n }\end{array}$ & $\begin{array}{l}19 \\
69\end{array}$ & $\begin{array}{l}5 \\
24\end{array}$ & $\begin{array}{l}13 \\
35\end{array}$ & $\begin{array}{l}1 \\
10\end{array}$ \\
\hline \multicolumn{5}{|l|}{ Adjuvant therapy } \\
\hline No, $n$ & 37 & 12 & 22 & 3 \\
\hline
\end{tabular}


Table 2 (Continued).

\begin{tabular}{|l|l|l|l|l|}
\hline Characteristic & Total $(\mathbf{n}=\mathbf{8 8})$ & LMS $(\mathbf{n}=\mathbf{2 9})$ & ESS $(\mathbf{n = 4 8 )}$ & Adenosarcoma $(\mathbf{n = 1} \mathrm{I})$ \\
\hline Chemotherapy, $\mathrm{n}$ & $4 \mathrm{I}$ & 13 & $2 \mathrm{I}$ & 7 \\
Chemotherapy+radiotherapy, $\mathrm{n}$ & 10 & 4 & 5 & 1 \\
\hline
\end{tabular}

Abbreviations: ESS, endometrial stromal sarcoma; LMS, leiomyosarcomas.

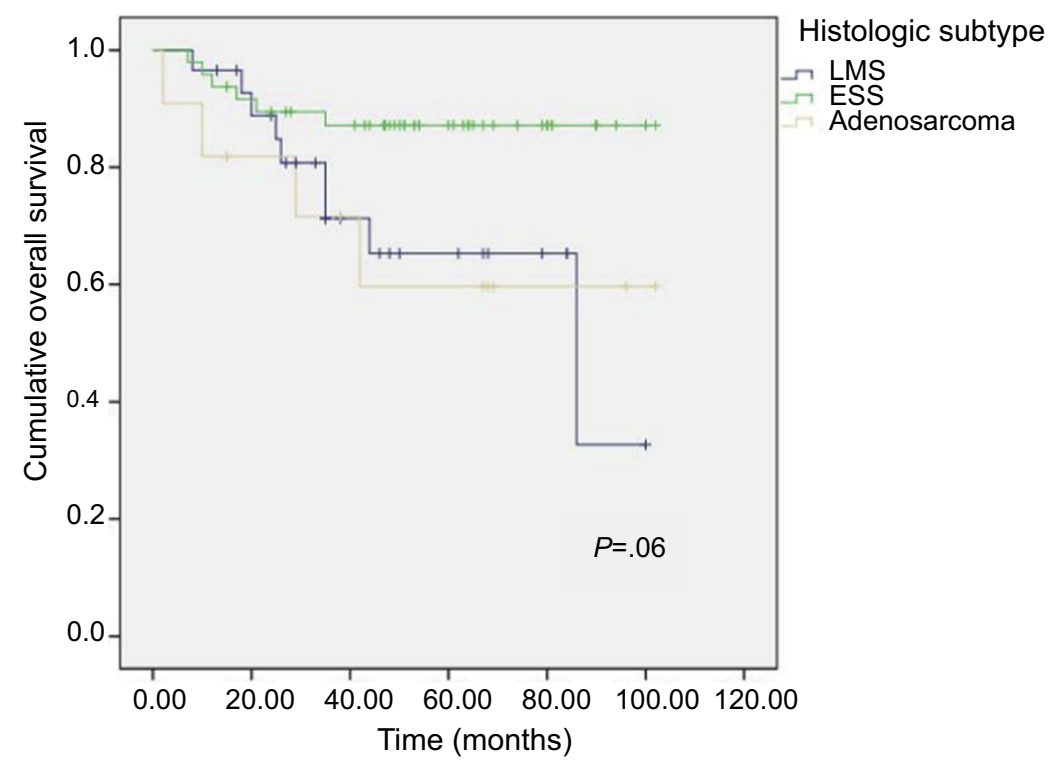

Figure I Overall survival curves for three subtypes.

Abbreviatons: ESS, endometrial stromal sarcoma; LMS, leiomyosarcomas.

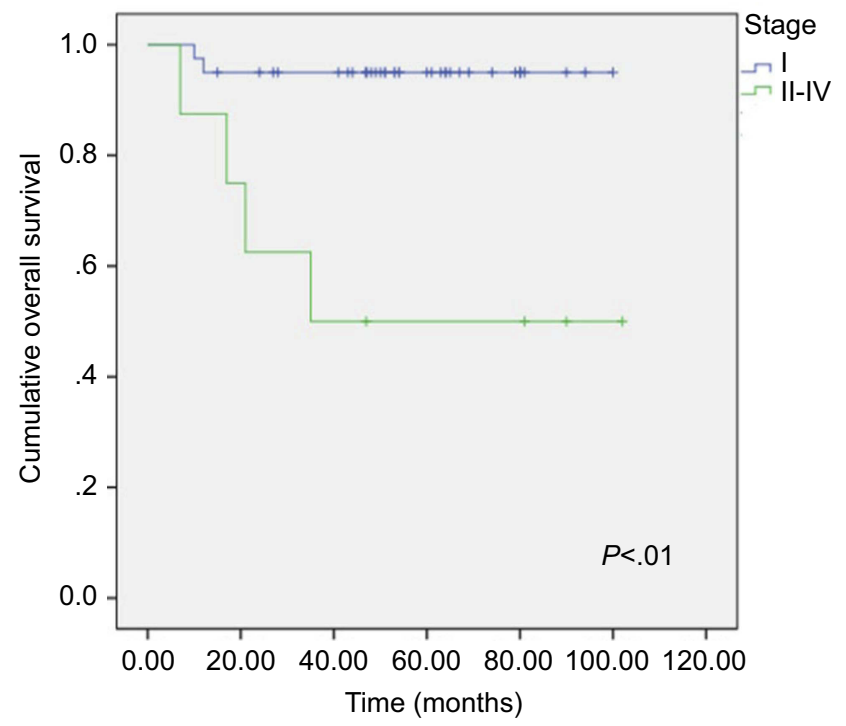

Figure 2 Overall survival curves for stages of endometrial stromal sarcoma in univariate analysis. 
based on the National Cancer Database, the largest analysis of women with LMS, not performing lymphadenectomy did not negatively impact survival. ${ }^{12}$ Previous studies have explored the risk of UUS for different age groups and reported that age was an independent prognostic factor for OS of uterine sarcomas. ${ }^{18}$ However, the current study did not find any significant association between age and survival of occult uterine sarcomas. Also in the current study, BMI ranged from 16.02 to $31.18 \mathrm{~kg} / \mathrm{m}^{2}$ but did not reveal a significant association between BMI and OS, while a previous cross-sectional study by Lin et al demonstrated a significant association between elevated BMI and poor quality of life. ${ }^{24}$ Being in perimenopause or after menopause was highest in the ESS group. Fibroids occur more frequently with increased exposure to estrogen. ${ }^{25}$ Therefore, women after menopause planning surgery for presumed benign leiomyoma found in clinical practice should especially beware. However, the state of menopause was not found to be associated independently with survival in UUS in the current study, which differs from the results of Gao et al. ${ }^{19}$ Although tumor size was found to have important prognostic value in previous studies, we failed to find its predictive value of prognosis even in LMS.

Table 3 Recent studies reporting the prevalence of unexpected uterine sarcomas

\begin{tabular}{|c|c|c|c|c|c|c|c|}
\hline First author & Year & Country & $\begin{array}{l}\text { Patients, } \\
\mathbf{N}\end{array}$ & $\begin{array}{l}\text { Primary } \\
\text { diagnosis }\end{array}$ & Intervention & $\begin{array}{l}\text { Total sar- } \\
\text { coma, } \mathbf{n}\end{array}$ & $\begin{array}{l}\text { Leiomyosar- } \\
\text { coma, } \mathbf{n}\end{array}$ \\
\hline Lieng 25 & 2014 & Norway & 4791 & Leiomyoma & $\begin{array}{l}\text { Hysterectomy or } \\
\text { myomectomy } \\
\text { 土morcellation }\end{array}$ & $20(0.42 \%)$ & $20(0.42 \%)$ \\
\hline Mahnert ${ }^{26}$ & 2015 & USA & 1325 & $\begin{array}{l}\text { Leiomyoma } \\
\text { 土abnormal uter- } \\
\text { ine bleeding }\end{array}$ & Hysterectomy & $5(0.38 \%)$ & ND \\
\hline Zhao $^{7}$ & 2015 & $\begin{array}{l}\text { People's Republic } \\
\text { of China }\end{array}$ & 10,248 & Leiomyoma & $\begin{array}{l}\text { Hysterectomy or } \\
\text { myomectomy } \\
\text { 土morcellation }\end{array}$ & $48(0.47 \%)$ & $13(0.13 \%)$ \\
\hline Paul $^{6}$ & 2016 & India & 2075 & Leiomyoma & $\begin{array}{l}\text { Myomectomy } \\
\pm \text { morcellation }\end{array}$ & $6(0.29 \%)$ & $2(0.10 \%)$ \\
\hline Zhang ${ }^{15}$ & 2016 & $\begin{array}{l}\text { People's Republic } \\
\text { of China }\end{array}$ & 3021 & Leiomyoma & $\begin{array}{l}\text { Hysterectomy } \\
\pm \text { morcellation }\end{array}$ & $18(0.60 \%)$ & $5(0.17 \%)$ \\
\hline Lee ${ }^{17}$ & 2016 & Korea & ND & Leiomyoma & $\begin{array}{l}\text { Hysterectomy or } \\
\text { myomectomy } \\
\text { 土morcellation }\end{array}$ & 45 & 18 \\
\hline Kho ${ }^{27}$ & 2016 & USA & 10,119 & Leiomyoma & $\begin{array}{l}\text { Hysterectomy } \\
\text { 土morcellation }\end{array}$ & $9(0.09 \%)$ & $5(0.05 \%)$ \\
\hline Raine-Bennett ${ }^{28}$ & 2016 & USA & 34,728 & Leiomyoma & $\begin{array}{l}\text { Hysterectomy } \\
\pm \text { morcellation }\end{array}$ & $125(0.36 \%)$ & $8 \mathrm{I}(0.23 \%)$ \\
\hline Ruengkhachorn ${ }^{29}$ & 2017 & Thailand & 11,258 & Leiomyoma & Hysterectomy & $22(0.20 \%)$ & $19(0.17 \%)$ \\
\hline Pavlakis ${ }^{30}$ & 2017 & Greece & 631 & Leiomyoma & $\begin{array}{l}\text { Hysterectomy or } \\
\text { myomectomy } \\
\text { 土morcellation }\end{array}$ & 8 (1.27\%) & 5 (0.79\%) \\
\hline Damasco ${ }^{24}$ & 2017 & Australia & 1878 & Leiomyoma & $\begin{array}{l}\text { Hysterectomy } \\
\pm \text { morcellation }\end{array}$ & $5(0.27 \%)$ & $0(0.0 \%)$ \\
\hline Current study & 2018 & $\begin{array}{l}\text { People's Republic } \\
\text { of China }\end{array}$ & 26,643 & Leiomyoma & $\begin{array}{l}\text { Hysterectomy or } \\
\text { myomectomy } \\
\text { 土morcellation }\end{array}$ & $88(0.33 \%)$ & $29(0.11 \%)$ \\
\hline
\end{tabular}

Abbreviation: ND, no data. 
Stage was found to be the unique prognostic factor in the current study in accordance with previous evidence. ${ }^{18,19}$ Moreover, the time interval between initial treatment (including neoadjuvant radiation or surgery) and secondary definitive surgery has been shown to impact outcomes of patients with gallbladder cancer. ${ }^{26}$ Possible explanations include the lack of a proper recovery period for subsequent tumor evaluation and pathologic diagnosis or lack of clear visualization through imaging examination after inflammation; this may be significant for management guidelines and follow-up surveillance. ${ }^{26}$ However, in the current study, a significant association between time interval and survival in UUS was not found.

In 2014, the US Food and Drug Administration announced a rate of 1 in 352 cases for UUS based on data from nine studies between 1990 and 2012. ${ }^{27}$ The most recent studies reporting the prevalence of UUS in surgery for presumed leiomyomas are noted in Table 3 and were published between 2012 and 2017. $6,7,18,20,28-35$ The maximum number of patients was 34,728 , and incidence of UUS ranged from $0 \%$ to $0.79 \%$. The current study population is the largest in recent years, and estimates of UUS and LMS found incidentally in patients undergoing hysterectomy and myomectomy were $0.33 \%$ and $0.11 \%$, respectively.

There are several limitations in the current study that should be taken into consideration. First, the nonrandomized, retrospective nature may limit standards for diagnosis and evaluation. Second, conducted in a university-based tertiary hospital, this study included many referral patients with more severe clinical presentations, including older age or larger palpable mass and may not be representative of the whole population and lead to selection bias. In addition, the follow-up time may appear to be insufficient. Third, owing to the small number of patients in the survival analysis, clinical significance of the prognostic factors should be accepted with caution. Moreover, our data were from a single center and the combined analysis of different histologic sarcoma types with different biological behavior in our study may decrease statistical power to demonstrate differences in prognosis.

\section{Conclusion}

Only $0.33 \%$ of patients who underwent surgery for presumed leiomyoma experienced UUS in the current study. ESS was the main subtype of UUS, and advanced stage appeared to be the adversely impact the prognosis of ESS Further multicenter, prospective clinical trials are warranted to substantiate these findings.

\section{Acknowledgments}

The study was supported by the National Natural Science Foundation of China (No 81572573) and the Graduate Student's Research and Innovation Fund of Sichuan University (Grant number 2018YJSY101).

\section{Disclosure}

The authors report no conflicts of interest in this work.

\section{References}

1. Laughlin SK, Schroeder JC, Baird DD. New directions in the epidemiology of uterine fibroids. Semin Reprod Med. 2010;28:204-217. doi:10.1055/s-0030-1251477

2. Cardozo ER, Clark AD, Banks NK, Henne MB, Stegmann BJ, Segars JH. The estimated annual cost of uterine leiomyomata in the United States. Am J Obstet Gynecol. 2012;206:e211-e219. doi:10.1016/j.ajog.2011.12.002

3. Styer AK, Rueda BR. The epidemiology and genetics of uterine leiomyoma. Best Pract Res Clin Obstet Gynaecol. 2016;34:3-12. doi:10.1016/j.bpobgyn.2015.11.018

4. Reichardt P. The treatment of uterine sarcomas. Ann Oncol. 2012;23 (Suppl 10):x151-x157. doi:10.1093/annonc/mds359

5. Reiter RC, Wagner PL, Gambone JC. Routine hysterectomy for large asymptomatic uterine leiomyomata: a reappraisal. Obstet Gynecol. 1992;79:481-484.

6. Paul PG, Rengaraj V, Das T, Garg R, Thomas M, Khurd AS. Uterine sarcomas in patients undergoing surgery for presumed leiomyomas: 10 years' experience. J Minim Invasive Gynecol. 2016;23:384-389. doi:10.1016/j.jmig.2015.11.012

7. Zhao WC, Bi FF, Li D, Yang Q. Incidence and clinical characteristics of unexpected uterine sarcoma after hysterectomy and myomectomy for uterine fibroids: a retrospective study of 10,248 cases. Onco Targets Ther. 2015;8:2943-2948.

8. Tan-Kim J, Hartzell KA, Reinsch CS, et al. Uterine sarcomas and parasitic myomas after laparoscopic hysterectomy with power morcellation. Am $J$ Obstet Gynecol. 2015;212:594.e1-594.e10. doi:10.1016/j.ajog.2014.12.002

9. Rovirosa A, Ascaso C, Ordi J, et al. Is vascular and lymphatic space invasion a main prognostic factor in uterine neoplasms with a sarcomatous component? A retrospective study of prognostic factors of 60 patients stratified by stages. Int $J$ Radiat Oncol Biol Phys. 2002;52:1320-1329. doi:10.1016/S03603016(01)02808-5

10. D'Angelo E, Espinosa I, Ali R, et al. Uterine leiomyosarcomas: tumor size, mitotic index, and biomarkers Ki67, and Bcl-2 identify two groups with different prognosis. Gynecol Oncol. 2011;121 (2):328-333. doi:10.1016/j.ygyno.2011.01.022

11. Abeler VM, Royne O, Thoresen S, Danielsen HE, Nesland JM, Kristensen GB. Uterine sarcomas in Norway. A histopathological and prognostic survey of a total population from 1970 to 2000 including 419 patients. Histopathology. 2009;54(3):355-364. doi:10.1111/j.1365-2559.2009.03231.x

12. Seagle BL, Sobecki-Rausch J, Strohl AE, Shilpi A, Grace A, Shahabi S. Prognosis and treatment of uterine leiomyosarcoma: a National Cancer Database study. Gynecol Oncol. 2017;145:61-70. doi:10.1016/j.ygyno.2017.02.012

13. Buscema J, McLellan R. Uterine sarcomas. In: Bieber EJ, Sanfilippo JS, Horowitz IR, Shafi MI, editors. Clinical Gynecology. Cambridge: Cambridge University Press; 2015:769-778.

14. D'Angelo E, Prat J. Uterine sarcomas: a review. Gynecol Oncol. 2010;116:131-139. doi:10.1016/j.ygyno.2009.09.023 
15. Nathenson MJ, Ravi V, Fleming N, Wang WL, Conley A. Uterine adenosarcoma: a review. Curr Oncol Rep. 2016;18:68. doi:10.1007/ s11912-016-0552-7

16. Prat J. FIGO staging for uterine sarcomas. Int J Gynaecol Obstet. 2009;104:177-178. doi:10.1016/j.ijgo.2008.12.008

17. Cantrell LA, Blank SV, Duska LR. Uterine carcinosarcoma: a review of the literature. Gynecol Oncol. 2015;137:581-588. doi:10.1016/j. ygyno.2015.03.041

18. Zhang J, Li T, Zhang J, Zhu L, Lang J, Leng J. Clinical characteristics and prognosis of unexpected uterine sarcoma after hysterectomy for presumed myoma with and without transvaginal scalpel morcellation. Int J Gynecol Cancer. 2016;26:456-463. doi:10.1097/IGC.0000000000000638

19. Gao Y, Meng H, Zhang Y, Jiao T, Hui N. Retrospective analysis of 80 cases with uterine carcinosarcoma, leiomyosarcoma and endometrial stromal sarcoma in China, 1988-2007. Int J Clin Exp Pathol. 2014;7:1616-1624.

20. Lee JY, Kim HS, Nam EJ, Kim SW, Kim S, Kim YT. Outcomes of uterine sarcoma found incidentally after uterus-preserving surgery for presumed benign disease. BMC Cancer. 2016;16:675. doi:10.1186/s12885-0162727-x

21. Cusidó M, Fargas F, Baulies S, et al. Impact of surgery on the evolution of uterine sarcomas. J Minim Invasive Gynecol. 2015;22:1068-1074. doi:10.1016/j.jmig.2015.05.024

22. Oduyebo T, Rauh-Hain AJ, Meserve EE, et al. The value of re-exploration in patients with inadvertently morcellated uterine sarcoma. Gynecol Oncol. 2014;132:360-365. doi:10.1016/j.ygyno.2013.11.024

23. Park JY, Park SK, Kim DY, et al. The impact of tumor morcellation during surgery on the prognosis of patients with apparently early uterine leiomyosarcoma. Gynecol Oncol. 2011;122:255-259. doi:10.1016/j. ygyno.2011.04.021

24. Lin LL, Brown JC, Segal S, Schmitz KH. Quality of life, body mass index, and physical activity among uterine cancer patients. Int J Gynecol Cancer. 2014;24:1027-1032. doi:10.1097/IGC.0000000000000166

25. Walker CL, Stewart EA. Uterine fibroids: the elephant in the room. Science. 2005;308:1589-1592. doi:10.1126/science.1112063

26. Ethun CG, Postlewait LM, Le N, et al. Association of optimal time interval to re-resection for incidental gallbladder cancer with overall survival: a multi-institution analysis from the US extrahepatic biliary malignancy consortium. JAMA Surg. 2017;152:143-149. doi:10.1001/ jamasurg. 2016.3642
27. FDA. Quantitative assessment of the prevalence of unsuspected uterine sarcoma in women undergoing treatment of uterine fibroids: summary and key findings 2014. Available from: http:// www.fda.gov/downloads/MedicalDevices/Safety/AlertsandNotices/ UCM393589.pdf. Accessed November 30, 2016.

28. Damasco MR, Chan PK, Slonim M, Ang WC, Healey MG. Incidence of malignancy and myoma variants at surgery for presumed benign symptomatic myomas. J Minim Invasive Gynecol. 2017;24:659-664. doi:10.1016/j.jmig.2017.02.012

29. Lieng M, Berner E, Busund B. Risk of morcellation of uterine leiomyosarcomas in laparoscopic supracervical hysterectomy and laparoscopic myomectomy, a retrospective trial including 4791 women. J Minim Invasive Gynecol. 2015;22:410-414. doi:10.1016/ j.jmig.2014.10.022

30. Mahnert N, Morgan D, Campbell D, Johnston C, As-Sanie S. Unexpected gynecologic malignancy diagnosed after hysterectomy performed for benign indications. Obstet Gynecol. 2015;125:397-405. doi:10.1097/AOG.0000000000000642

31. Kho KA, Lin K, Hechanova M, Richardson DL. Risk of occult uterine sarcoma in women undergoing hysterectomy for benign indications. Obstet Gynecol. 2016;127:468-473. doi:10.1097/ AOG.0000000000001242

32. Raine-Bennett T, Tucker LY, Zaritsky E, et al. Occult uterine sarcoma and leiomyosarcoma incidence of and survival associated with morcellation. Obstet Gynecol. 2016;127:29-39. doi:10.1097/ AOG.0000000000001187

33. Ruengkhachorn I, Phithakwatchara N, Nawapun K, Hanamornroongruang S. Undiagnosed uterine sarcomas identified during surgery for presumed leiomyoma at a national tertiary hospital in Thailand: a 10-year review. Int $J$ Gynecol Cancer. 2017;27:973-978. doi:10.1097/IGC.0000000000000968

34. Pavlakis K, Messini I, Yiannou P, et al. Morcellating uterine mesenchymal tumors: the pathologist's view. J Obstet Gynaecol Res. 2017;43:580-586. doi:10.1111/jog.13201

35. Yang H, Li XC, Yao C, et al. Proportion of uterine malignant tumors in patients with laparoscopic myomectomy: a national multicenter study in China. Chin Med J. 2017;130:2661-2665. doi:10.4103/03666999.218008

\section{Publish your work in this journal}

Cancer Management and Research is an international, peer-reviewed open access journal focusing on cancer research and the optimal use of preventative and integrated treatment interventions to achieve improved outcomes, enhanced survival and quality of life for the cancer patient.
The manuscript management system is completely online and includes a very quick and fair peer-review system, which is all easy to use. Visit http://www.dovepress.com/testimonials.php to read real quotes from published authors. 